\title{
Ni-Catalyzed Sonogashira Coupling of Nonactivated Alkyl Halides
}

\section{Key words}

Sonogashira coupling

terminal alkynes

alkylation

alkyl halides

nickel

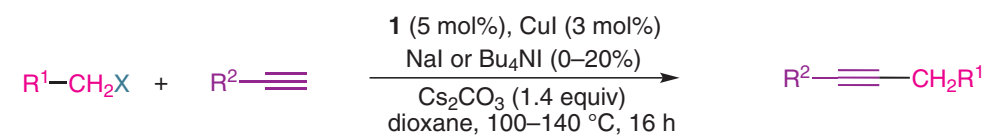

Examples:

$\mathrm{EtO}_{2} \mathrm{C}\left(\mathrm{CH}_{2}\right)_{3}=\mathrm{CH}_{2} \mathrm{OTMS}$

$X=1,73 \%$ yield

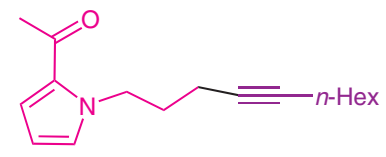

$X=I, 61 \%$ yield

$\mathrm{Et}_{2} \mathrm{NOC}\left(\mathrm{CH}_{2}\right)_{5}=n-\mathrm{Hex}$
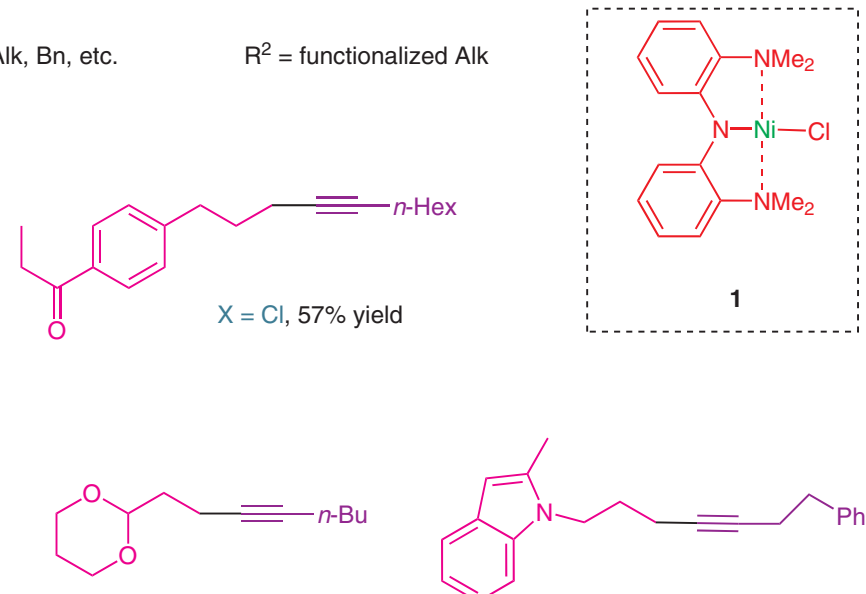

$\mathrm{X}=\mathrm{Br}, 61 \%$ yield

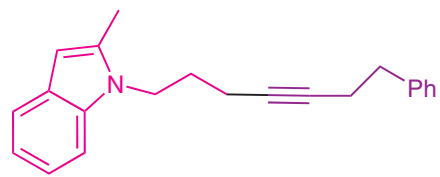

$\mathrm{X}=\mathrm{Cl}, 75 \%$ yield

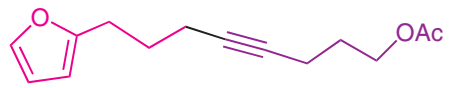

$\mathrm{X}=\mathrm{Cl}, 64 \%$ yield
Significance: The Sonogashira cross-coupling of nonactivated, $\beta-\mathrm{H}$-containing alkyl halides is a highly challenging reaction. Use of nickel(II) pincer complex 1, developed by the authors, allows for a simple and versatile coupling of functionalized alkyl halides, including chlorides, with various terminal alkynes. This is an excellent method for the preparation of internal alkynes.
Comment: The nickel(II) pincer complex $\mathbf{1}$ is also a versatile catalyst for the Kumada $\mathrm{sp}^{3}-\mathrm{sp}^{2} \mathrm{cou}$ pling (O. Vechorkin, V. Proust, X. L. Hu J. Am. Chem. Soc. 2009, 131, 9756). Contrary to the classical Sonogashira coupling, aryl halides are not reactive under these conditions. This method is more convenient than the classical alkyne alkylation, which requires harsh basic conditions. 